\title{
Metal and metalloid exposure and oxidative status in free-living individuals of Myotis daubentonii
}

\section{Ruiz, Sandra R.}

2019-03

Ruiz , S R , Eeva , T , Kanerva , M , Blomberg , A \& Lilley , T M 2019 , ' Metal and metalloid exposure and oxidative status in free-living individuals of Myotis daubentonii ' , Ecotoxicology and Environmental Safety, vol. 169 , pp. 93-102 . https://doi.org/10.1016/j.ecoenv.2018.10.083

http://hdl.handle.net/10138/321391

https://doi.org/10.1016/j.ecoenv.2018.10.083

cc_by_nc_nd

acceptedVersion

Downloaded from Helda, University of Helsinki institutional repository.

This is an electronic reprint of the original article.

This reprint may differ from the original in pagination and typographic detail.

Please cite the original version. 


\section{Metal and metalloid exposure and oxidative status in free- 2 living individuals of Myotis daubentonii}

3

4 Sandra R. Ruiz ${ }^{\text {a* }}$, Tapio Eeva ${ }^{\mathrm{a}}$, Mirella Kanerva ${ }^{\mathrm{a}}$, Anna Blomberg ${ }^{\mathrm{a}}$ and Thomas

$5 \quad$ M. Lilley ${ }^{\mathrm{b}, \mathrm{c}}$

$6 \quad{ }^{a}$ Department of Biology, University of Turku, 20014 Turku, Finland

$7 \quad{ }^{b}$ Institute of Integrative Biology, University of Liverpool, Liverpool, UK

$8 \quad{ }^{c}$ Finnish Museum of Natural History, University of Helsinki, Helsinki, Finland

$9 \quad *$ Corresponding author: srruiz@utu.fi

10

11

12

13

14

15

16

17

18

19

20

21

22

23

24

25

26

27

28

29 
Metal elements, ubiquitous in the environment, can cause negative effects in long-lived organisms even after low but prolonged exposure. Insectivorous bats living near metal emission sources can be vulnerable to such contaminants. Although it is known that bats can bioaccumulate metals, little information exists on the effects of metal elements on their physiological status. For example, oxidative status markers are known to vary after detoxification processes and immune reactions. Here, for two consecutive summers, we sampled individuals from a natural population of the insectivorous bat, Myotis daubentonii, inhabiting a site close to a metal emission source. We quantified metals and metalloids (As, $\mathrm{Ca}, \mathrm{Cd}, \mathrm{Co}, \mathrm{Cu}, \mathrm{Mn}, \mathrm{Ni}, \mathrm{Pb}, \mathrm{Se}, \mathrm{Zn}$ ) from individual fecal pellets. We measured enzymatic antioxidants (GP, CAT, SOD), total glutathione (tGSH) and ratio between reduced and oxidized glutathione (GSH:GSSG) from their red blood cells together with biometrics, hematocrit and parasite prevalence. In general, metal concentrations in feces of $M$. daubentonii reflected the exposure to ambient contamination. This was especially evident in the higher concentrations of $\mathrm{Cd}, \mathrm{Co}, \mathrm{Cu}$ and $\mathrm{Ni}$ close to a smelter compared to a site with less contaminant exposure. Annual differences were also observed for most elements quantified. Sex-specific differences were observed for calcium and zinc excretion. SOD and CAT enzymatic activities were associated with metal levels (principal components of six metal elements), suggesting early signs of chronic stress in bats. The study also shows promise for the use of non-invasive sampling to assess the metal exposure on an individual basis and metal contamination in the environment. 


\section{Introduction}

Bats are vulnerable to the exposure of various environmental pollutants, including organic contaminants and heavy metals (Walker et al. 2007, Naidoo et al. 2013, Bayat et al. 2014, Zukal et al. 2015). The longevity (Salmon et al. 2009, Munshi-South and Wilkinson 2010) and high trophic position of bats increases the likelihood of bioaccumulating pollutants in their tissues (Senthilkumar et al. 2001, Wada et al. 2010, Zukal et al. 2015). Population-level adverse effects associated with sustained contaminant exposure have been found (Gerell and Lundberg 1993), while individual cases of metal and pesticide poisoning have been anecdotically reported (Zook et al. 1970, Sutton and Wilson 1983, Skerratt et al. 1998). Metal-related effects in bats can be genotoxic (Zocche et al. 2010, Karouna-Renier et al. 2014, Naidoo et al. 2015), neurologic (Nam et al. 2012) and immunological (Pilosof et al. 2014), all generally linked to a continued chronic exposure.

Metal elements occur naturally in the environment (Tchounwou et al. 2012). However, anthropogenic activities including industrial (mining, smelting), agricultural (pesticide and fertilizer application), domestic (lead-based paint and leaded-gasoline exhaust) and technological applications have contributed to the increment and spread of metals in various terrestrial and aquatic ecosystems (Hoffman et al. 2003). Particularly, industrial activities emit a combination of metals into the atmosphere, which end up deposited into soil and living matters such as plants and soil-dwelling invertebrates. Thus, metals also enter the food chain, e.g. through invertebrate diet items consumed by higher-trophic positioned animals (Park et al. 2009, Lilley et al. 2012, Méndez-Rodríguez and Alvarez-Castañeda 2016).

Long-term toxicant exposure can cause immune system disturbances, antioxidant depletion and DNA damage (Zocche et al. 2010, Lilley et al. 2013, Stauffer et al. 2017). Heavy metals can modulate immunological responses, for example impairing phagocytic activity of the exposed individual (Boyd 2010). One of the proposed mechanisms of metal toxicity is via oxidative stress (Valko et al. 2005, Regoli et al. 2011), which is the imbalance between antioxidants and oxygen radicals. Oxidative stress as a response to metal related toxicity has been described for wildlife (Regoli et al. 2011, Costantini et al. 2014). In bats, oxidative status markers have been analysed in relation to immune challenge (Schneeberger et al. 2013), but studies investigating the effects of environmental pollutants in relation to oxidative status are more scarce (Lilley et al. 2013). The combination of industrial disturbance, habitat destruction 
and parasite presence can result in physiological stress (Gerell and Lundberg 1993, Kannan et al. 2010). One of the host responses to parasite infestation may be an excessive production of oxygen radicals by phagocytic cells, also referred to as oxidative burst (Costantini 2014).

Here, we measure oxidative status of free-living insectivorous bats exposed to industrial metal pollution. We studied Daubenton's bat (Myotis daubentonii) individuals from geographically separated natural populations, one of which roosted and forage close to a source of metal emissions i.e. a Copper $(\mathrm{Cu})$ - Nickel $(\mathrm{Ni})$ smelter and other individuals at a less contaminated site. In bats, studies linking toxicant challenge to physiological alterations unfortunately have mostly required destructive sampling, since internal organs have been used to determine metal concentrations. Here, we collected individual bat fresh fecal pellets to quantify the following elements: Arsenic (As), Calcium (Ca), Cadmium (Cd), Cobalt (Co), Cu, Manganese (Mn), Lead (Pb), Ni, Selenium (Se) and Zinc ( $\mathrm{Zn})$. In addition, we extracted a minimal amount of blood from the same individuals to measure markers of oxidative status: the ratio between Reduced Glutathione (GSH) and Oxidized Glutathione (GSSG) i.e. GSH:GSSG ratio and the enzymatic activities of Glutathione Peroxidase (GP), Catalase (CAT) and Superoxide Dismutase (SOD). Based on oxidative status alterations found in other small mammals exposed to toxic metals (Viegas-Crespo et al. 2003), we hypothesize that the metalexposed bats develop oxidative stress in response to elevated toxic metals in the environment at contaminated sites compared to our less contaminated reference site. However, given the unique characteristics of insectivorous bats, i.e. use of torpor, longevity and high basal antioxidants compared to other mammals (Wilhelm Filho et al. 2007), it is possible that the antioxidant machinery in bats may counteract metal-related challenges. This is the first study reporting physiological oxidative status effects of metal contamination on non-captive bat individuals.

\section{Materials and methods}

\subsection{Study species and study area}

Bats were trapped during May-August 2014 and 2015 in the vicinity of a smelter in Harjavalta $\left(61^{\circ} 20^{\prime} \mathrm{N}, 22^{\circ} 10^{\prime} \mathrm{E}\right)$, and at an old water mill in Lieto $\left(60^{\circ} 33^{\prime} \mathrm{N}, 22^{\circ} 27^{\prime} \mathrm{E}\right)$ with a combination of harp traps and mist nets (2.5 m height; Ecotone, Poland) placed along flying corridors during their emergence time from roosting sites in Harjavalta $(n=32)$, and hand trapped into cloth bags 
in Lieto ( $\mathrm{n}=19)$. Myotis daubentonii, is an insectivorous trawling bat distributed across Europe and Asia. The species roosts in tree cavities, but they also take human-made constructions i.e. bird boxes or buildings (Joint Nature Conservation Committee 2007, Dietz et al. 2009). Myotis daubentonii roosts close to water bodies, where it forages for insects, mainly Chironomidae (Dietz et al. 2009, Encarnação et al. 2010, Vesterinen et al. 2016). Chironomids, or non-biting flying midges spend a part of the life-cycle as filter-feeders within sediments of water bodies. They are therefore prone to accumulate chemicals or toxicants discharged into the water bodies and deposited over time in the water bottom (Lilley et al. 2012).

Myotis daubentonii normally breed in colonies, and they can form subgroups within a colony due to their mobility thus not being loyal to a specific roosting site within a cave. However, individuals do show area roost fidelity (Lucan and Hanak 2011, Ngamprasertwong et al. 2014). Generally, M. daubentonii become sexually mature at their first year, being able to reproduce in late summer (Encarnação et al. 2004). However, observations of male $M$. daubentonii being sexually matured at their year of birth and consequently being able to reproduce before their first hibernation period have been reported (Encarnação et al. 2006).

Here, we sampled a bat population in a forest patch close to an air metal emission point source in Harjavalta, Western Finland. Harjavalta is an industrial town characterized for its metal processing activities particularly the smelting of copper and nickel (Kiikkilä 2003). Emissions also include arsenic, zinc, cadmium, mercury, lead and sulphur as the smelting process by-products (Kiikkilä 2003). A river, Kokemäenjoki, runs through the town and is the main feeding ground for the bats in our study. This river system has a large catchment basin $\left(27000 \mathrm{~km}^{2}\right)$ including $16 \%$ of agricultural land (Huttunen et al. 2016). In 2014, an accidental metal discharge from the smelter in Harjavalta released 66 tons of nickel into the Kokemäenjoki-river (KVVY ry. 2016). The second and less metal exposed bat group in our study, roosts in an old water mill in Lieto. This bat population has been previously monitored for some years (Laine et al. 2013, Vesterinen et al. 2016), but the metals are quantified for the first time in this study. The water mill is located along the Aura-river in South-Western Finland and has a catchment basin of $874 \mathrm{~km}^{2}$ of which $37 \%$ is agricultural land (Huttunen et al. 2016).

\subsection{Sampling and biometric measurements}

Caught bats were identified to species and banded. Weight was recorded to the nearest $0.1 \mathrm{~g}$ with a Pesola spring balance and forearm length was recorded to the nearest $0.05 \mathrm{~mm}$ with a sliding caliper. Sex was determined, and age was classified into adults and juveniles according 
to the ossification state between phalanges (Brunet-Rossinni and Wilkinson 2009). Fur and wing were inspected for ectoparasites. Bats often defecate when handled, thus fresh fecal pellets were collected per individual and used for metal analysis. Blood was obtained (up to a maximum of $65 \mu \mathrm{L}$ ) from the interfemoral vein into a heparinized capillary tube (Marienfield 80iu/ml) and immediately centrifuged at $4400 \mathrm{~g}$ for 5 minutes in a LW Scientific ZIPocrit Hematocrit Centrifuge to separate the red blood cell fraction from plasma. The hematocrit (proportion of red cells) was measured with a sliding caliper. The red blood cells and plasma were placed separately into tubes, flash frozen in liquid nitrogen and stored at $-80{ }^{\circ} \mathrm{C}$ until the oxidative marker analyses. The blood metal concentrations were not measured because there was not enough blood material to quantify both the metals and oxidative status parameters. All bats were released after sampling. Collection licences were approved by the Animal Ethics Committee of the University of Turku (license number ESAVI/3221/04.10.07/2013) and Centre for Economic Development, Transport and the Environment (license number VARELY/948/2015).

\subsection{Metal analysis}

Fecal pellets (one sample belonging to one individual) were dried separately at $50^{\circ} \mathrm{C}$ for 48 hours. Dried samples were weighted and dissolved in a mixture of Suprapure acids, $3 \mathrm{~mL} \mathrm{HNO}_{3}$ and $1 \mathrm{~mL} \mathrm{H}_{2} \mathrm{O}_{2}$ with a microwave digestion system (Anton Paar Microwave Sample preparation System, Multiwave 3000). After that, samples were diluted to $50 \mu \mathrm{L}$ per sample with de-ionized water. The elements chosen for quantification were: the essential elements (Ca, $\mathrm{Co}, \mathrm{Cu}, \mathrm{Mn}, \mathrm{Ni}$, Se and $\mathrm{Zn})$, the non-essential metals $(\mathrm{Cd}, \mathrm{Pb})$ and the non-essential metalloid (As). Generally, most of these chosen elements have been referred to as "heavy metals". Although no chemical consensus (e.g. atomic number, density, etc.) exists in the definition of "heavy metals" (Duffus 2002), the term is widely used in environmental sciences to refer to a group of metals, metalloids and other elements or compounds which exert toxicity. In this manuscript, when referring to all the selected elements we quantified, we will address them as "metals" or "metal elements" since this arbitrary grouping includes essential and non-essential metals as well as metalloids.

The determination of metal element concentrations was conducted with inductively coupled plasma mass spectrometer ICP-MS (Elan 6100 DRC+ from PerkinElmer-Sciex), by using a quantitative standard mode. The detection limit for most of the metal elements was around 1 ppt (ng/L) and below. The instrument was calibrated with a commercial multistandard from Ultra Scientific, IMS-102, ICP-MS calibration standard 2. Certified reference 
materials from European Reference Material (mussel tissue ERM-CE278K-8G) were used for method validation. In 2014, the mean recoveries $( \pm$ SE) in nine reference samples were as follows: Ca $98 \pm 15.98 \%$, Mn $98 \pm 3.29 \%$, Co $101 \pm 1.52 \%$, As $96 \pm 1.79 \%$, Pb $95 \pm 3.25 \%$, Ni $120 \pm 2.41 \%$, Cu $100 \pm 2.44 \%$, Cd $91 \pm 1.79 \%$, Zn $87 \pm 1.80 \%$, Se $151 \pm 26.20 \%$. In 2015, the mean recoveries $( \pm \mathrm{SE})$ in six reference samples were as follows: Ca $113 \pm 8.39 \%$, Mn 112 $\pm 4.21 \%$, Co $101 \pm 2.25 \%$, As $99 \pm 1.24 \%$, Pb $89 \pm 2.05 \%$, Ni $111 \pm 4.85 \%$, Cu $100 \pm 2.43 \%$, $\mathrm{Cd} 92 \pm 1.90 \%$, Zn $93 \pm 1.51 \%$, Se $118 \pm 5.44 \%$. The results are expressed as $\mu \mathrm{g} / \mathrm{g}$ on a dry weight (d.w.) basis.

\subsection{Oxidative status analysis}

Concentrations of antioxidants and enzymatic activities were measured from red blood cells in triplicate using 96-well and 384-well microplates. Protein content was determined using the Bradford method with bovine serum albumin as a standard and BioRad protein assay reagent (Bradford 1976). The samples were diluted in phosphate buffer saline before being added to the microplate. Inter-assay variation was normalized by using the same control samples of known enzymatic activities. Measurements were obtained using EnSpire and Envision plate readers (Perkin-Elmer).

\subsubsection{Glutathione}

Glutathione, an important cellular antioxidant used as a substrate for the enzyme glutathioneS-transferase in Phase II detoxification of chemicals (Sies 1999) was quantified in its reduced (GSH) and oxidized form i.e. glutathione disulphide (GSSG) using a ThioStar glutathione detection reagent purchased from Arbor Assays. First, samples were pre-processed by removing proteins with a solution of $5 \%$ sulfosalicylic acid, then diluted to $1 \%$ SSA with sample dilution buffer. In a 384-well black microplate (Perkin Elmer), $6.5 \mu \mathrm{L}$ of Thiostar reagent was added to $12.5 \mu \mathrm{L}$ of standard, sample or blank, incubated in dark for 15 minutes and fluorescence emission measured at $510 \mathrm{~nm}$, with excitation of $405 \mathrm{~nm}$ to determine the free GSH concentration. Then, $6.5 \mu \mathrm{L}$ of reaction mixture ( $4 \mathrm{mM} \mathrm{NADPH}+8 \mathrm{U} / \mathrm{ml} \mathrm{GR}$ ) were added, incubated for 15 minutes and fluorescence measured at same excitation and emission wavelengths to determine the total glutathione concentration ( $\mathrm{tGSH}$ ), expressed as $\mu \mathrm{mol} / \mathrm{mg}$.

\subsubsection{Glutathione Peroxidase}

Glutathione Peroxidase (GP) Cellular Activity Assay Kit was purchased from Sigma (Catalog No CGP1). Glutathione peroxidase activity is determined indirectly, by first quantifying the 
conversion of reduced glutathione (GSH) to oxidized glutathione (GSSG), followed by the reduction of GSSG back to GSH, catalyzed by the enzyme glutathione reductase (GR) and Nicotinamide Adenine Dinucleotide Phosphate Reduced (NADPH). Procedures were carried out following the manufacturer instructions, except using $2 \mathrm{mM} \mathrm{H} \mathrm{O}_{2}$ as a substrate. The assay was performed in a clear 384-well plate (Perkin Elmer). Briefly, to each well were added: 35 $\mu \mathrm{L}$ of assay buffer, $5 \mu \mathrm{L}$ of NADPH assay reagent, $5 \mu \mathrm{L}$ of $2 \mathrm{mM} \mathrm{H}_{2} \mathrm{O}_{2}$ and $5 \mu \mathrm{L}$ of blood sample to obtain a final volume of $50 \mu \mathrm{L}$. Five $\mu \mathrm{L}$ of assay buffer were used as blank. The absorbance was measured at $340 \mathrm{~nm}$ (A340) for 60 seconds in a kinetic program using an Envision microplate spectrophotometer. The activity of GP was calculated by dividing the A340 by the extinction coefficient of NADPH (6.22) and it is expressed as pmol/min/mg.

\subsubsection{Catalase}

The activity of catalase (CAT), an enzyme which converts hydrogen peroxide into water and oxygen, was quantified following the protocol instructions of the CAT-assay kit (Sigma Catalog No CAT 100). To perform the assay in a 96-well microplate format, the volumes of reagents and samples were reduced. Assay solutions (peroxide, peroxide-solution, assay buffer, chromogen, Sodium Azide $\left(\mathrm{NaN}_{3}\right)$ - stop solution and enzyme dilution buffer) were prepared according to the information in the Sigma kit technical bulletin. Briefly, $2 \mu \mathrm{L}$ of sample $(1 \mathrm{mg} / \mathrm{mL})$ and $13 \mu \mathrm{L}$ of assay buffer were mixed in a tube. The reaction was stopped with 180 $\mu \mathrm{L}$ of $15 \mathrm{mM} \mathrm{NaN}$. The CAT activity expressed in $\mu \mathrm{mol} / \mathrm{min} / \mathrm{mg}$ was colorimetrically quantified by adding $200 \mu \mathrm{L}$ chromogen in each well to $2 \mu \mathrm{L}$ aliquot of the stopped reaction solution. Absorbance was measured at $520 \mathrm{~nm}$.

\subsubsection{Superoxide Dismutase}

Superoxide dismutase (SOD) assay kit was purchased from Sigma-Aldrich (Catalog No 19160). The reaction determines the inhibition activity of SOD by a colorimetric method. The water-soluble salt WST-1 (2-(4-Iodophenyl)-3-(4-nitrophenyl)-5-(2,4-disulfophenyl)-2Htetrazolium, monosodium salt) reacts with the superoxide anion to produce a formazan dye. The reduction rate of reduced superoxide anion (i.e. $\mathrm{O}_{2}^{-}$) is directly related to the enzyme xanthine oxidase (XO) which is inhibited by SOD. In a 384 -well plate, $45 \mu \mathrm{L}$ of WST-solution were added to $5 \mu \mathrm{L}$ of sample $(1 \mathrm{mg} / \mathrm{mL})$. Then $5 \mu \mathrm{L}$ of xanthine oxidase (XO) enzyme were added to each well and incubated at $37^{\circ} \mathrm{C}$ for $20 \mathrm{~min}$. Absorbance was measured at $450 \mathrm{~nm}$. SOD activity is expressed as inhibition rate percentage. 


\subsection{Statistics}

We used a dataset including Harjavalta and Lieto observations for which metal data was available during 2014 and $2015(n=51)$. To explain variation in biometric data $(n=50)$, we built linear models (LMs) separately for body mass and forearm length (using the Glimmix procedure) in SAS 9.4. In these models, we included year, sex, age, location and the interaction between year and location as explanatory variables. For a more complete picture of the health condition of bats, we also analyzed the effect of the same explanatory variables on hematocrit (ratio between red blood cells and whole blood volume; $n=44$ ) and parasite prevalence (in wings and fur; $n=51$ ). We used generalized linear models (GLM) for parasite prevalence.

We analyzed the correlations between metals with Pearson correlation analysis and investigated variation in metal element concentrations ( $\mathrm{As}, \mathrm{Ca}, \mathrm{Cd}, \mathrm{Co}, \mathrm{Cu}, \mathrm{Mn}, \mathrm{Ni}, \mathrm{Pb}, \mathrm{Se}$, $\mathrm{Zn})$ in individual bat feces $(\mathrm{n}=51)$ using the same explanatory variables used for biometrics i.e. year, sex, age location and the interaction between year and location. Terms were removed if not significant, one at a time starting with interactions. The metal concentrations were log-10 transformed before analysis to comply with normality requirements in the model. We also use Pearson correlation analysis to examine the associations of metals with parasite prevalence, biometric data and oxidative status parameters (log-10-transformed SOD, CAT, tGSH, GSH:GSSG and GP).

For further modelling of the effects of pollution level on morphological and physiological parameters we built principal components (PC) of six metal elements (As, Cd, $\mathrm{Co}, \mathrm{Cu}, \mathrm{Ni}, \mathrm{Pb}$ ) to reduce the information of multiple inter-correlated variables (metal concentrations) into smaller number of variables, or components, explaining most of the variation in the data. The selection of these elements was based on their toxic degree (Tchounwou et al. 2012), their strong correlation with each other and their consistent elevated concentrations around the smelter source. The effects of metal exposure may negatively affect vital physiological functions potentially leading to body mass loss (Eeva and Lehikoinen 1996, Dauwe et al. 2006). We investigated this in a model with the first and second principal components of metals (PC1, PC2) as an explanatory variable for body mass and with sex, age and location as additional explanatory variables. Because some of the studied non-essential metals capable of toxicity (e.g. $\mathrm{Cd}$ and $\mathrm{Pb}$ ) can interfere with calcium metabolism and in turn, calcium concentration in the body may affect bone development, we included calcium as a predictor of forearm length. In this LM we included age, but not sex, because age represents an important source of variation for forearm length in our data. Given the significant 
correlations found between SOD and CAT with many metal elements known to cause toxic effects ( $\mathrm{As}, \mathrm{Co}, \mathrm{Cu}, \mathrm{Ni}$ and $\mathrm{Pb}$ ), we explored the effects of the first and second principal components of metals (PC1, PC2) on these two oxidative status markers in a model including also year as an explanatory variable.

All variables were modeled with Gaussian error distribution, except parasite prevalence, which was built with binary error distribution. Geometric means of metal concentrations and 95\% confidence intervals were calculated and back-transformed from models to express the fold-level comparisons between explanatory variables. Similarly, estimates and standard errors from the models are shown for biometrics.

\section{Results}

\subsection{Biometrics}

Adult bats weighed more than juveniles $\left(\mathrm{F}_{\mathrm{df}}=44.59_{1,47}, \mathrm{p}<0.01\right.$, Table 1) and bats in Harjavalta were heavier than in Lieto $\left(\mathrm{F}_{\mathrm{df}}=14.71_{1,47}, \mathrm{p}<0.01\right.$, Table 1$)$. Body mass did not vary between years, nor did we observe significant sex-related differences in body mass (Table 1). The forearm length of adults was significantly larger than juveniles $\left(F_{d f}=40.83_{1,47}, p<0.01\right.$, Table 1). Females had larger forearms (Estimate \pm SE: $37.44 \pm 0.25 \mathrm{~mm}, \mathrm{n}=20$, Table 1) compared to males (Estimate \pm SE: $36.70 \pm 0.28 \mathrm{~mm}, \mathrm{n}=40$, Table 1 ). Hematocrit did not vary by sex, age, year or location (Table 1).

\subsection{Parasite load}

Parasite prevalence on wings, defined as the presence of one or more ectoparasites in the wing membrane (mites, Spinturnicidae) was significantly different between years and locations: bats from Harjavalta showed higher mite prevalence on their wings compared to Lieto ones $\left(\mathrm{F}_{\mathrm{df}}=12.33_{1,48}, \mathrm{p}<0.01\right.$, Table 1$)$, and wing parasite prevalence was greater during 2015 $\left(\mathrm{F}_{\mathrm{df}}=4.56_{1,48}, \mathrm{p}=0.04\right.$, Table 1). Parasite prevalence in fur, defined as the presence of bat flies (Nycteribidae) also varied by location but this effect was different in two years (Year*Location: $\mathrm{F}_{\mathrm{df}}=6.07_{1,47}, \mathrm{p}=0.02$, Table 1). We observed positive significant correlations between wing mites with cadmium $(r=0.35, p=0.01, n=51)$ and copper $(r=0.29, p=0.04, n=51)$, and a negative association with lead $(\mathrm{r}=-0.30, \mathrm{p}=0.03, \mathrm{n}=51)$. Bat flies in fur were negatively correlated with $\operatorname{arsenic}(\mathrm{r}=-0.30, \mathrm{p}=0.03, \mathrm{n}=51)$ and cobalt $(\mathrm{r}=-0.34, \mathrm{p}=0.02, \mathrm{n}=51)$.

\subsection{Metal levels}


Overall, elevated concentrations of cobalt, copper, cadmium and nickel were found around the Harjavalta smelter area compared to the water mill Lieto bats, particularly during the first year of the study. However, surprisingly elevated levels of lead were observed around the water mill during the second study year.

Cobalt, copper and nickel were detected at higher concentrations in Harjavalta compared to Lieto (Table 2, Figure 1). The concentrations of these elements also decreased from 2014 to 2015 within Harjavalta (Table 2, Figure 1, Table S1). Cadmium was overall markedly higher (i.e. 4.8-times) in Harjavalta compared to Lieto (Table 2, Figure 1, Table S1), and 1.9-times higher in 2014 compared to the following year (Table 2, Figure 1, Table S1). Selenium followed the same annual trends as cadmium. However, contrary to cadmium and most other metals (except lead), selenium was significantly higher (i.e. 3.1-times) in Lieto than in Harjavalta (Table 2, Table S1). Manganese only varied annually, being 2.0-times higher in 2014 than 2015 (Table 2, Table S1). Age had no effect in metal element levels (Table 2). Means $( \pm \mathrm{SE})$ for each element are given in supplementary Table $\mathrm{S} 1$.

For reasons unknown, lead was on average 8.9-times higher in the water mill bats in Lieto than around the smelter in Harjavalta during 2015 (Table 2, Table S1). Arsenic concentration was not significantly different among years or locations (Table 2).

Calcium was 1.8-times higher in 2014 compared to the following year, 2.0 times higher in Lieto than in Harjavalta and 1.9-times higher in males than in females (Table 2, Figure 2, Table S1). In contrast, zinc concentrations were 1.4-times higher in females than males (Table 2, Figure 2, Table S1). Same annual trends as in calcium were also observed for zinc i.e. higher concentrations in the first year of sampling (Table 2, Table S1). Correlations between metals are presented in supplementary Table S2.

The principal component analysis (PCA) of metal elements including As, $\mathrm{Cd}, \mathrm{Co}, \mathrm{Cu}$, $\mathrm{Ni}$ and $\mathrm{Pb}$ revealed two principal components with eigenvalues larger than one. The first principal component $(\mathrm{PC} 1$, eigenvalue $=3.05)$ represented $51 \%$ of the total variation, the main loadings coming from $\mathrm{Cd}, \mathrm{Co}, \mathrm{Cu}$ and $\mathrm{Ni}$. The second principal component (PC2, eigenvalue $=1.60$ ) represented $27 \%$ of the variation with main loadings from $\mathrm{As}$ and $\mathrm{Pb}$ and in a smaller manner Ni.

\subsection{Metals and biometrics}


The second, but not first, principal component of metals (PC2) had a significant negative association to body mass, when age was considered as an additional explanatory variable in the same model (PC2: $F_{d f}=5.20_{1,47}, p=0.0271$; Age: $\left.F_{d f}=31.21_{1,47}, p<0.0001\right)$, adult bats being heavier the smaller the metal load was. Forearm length showed an age-related negative

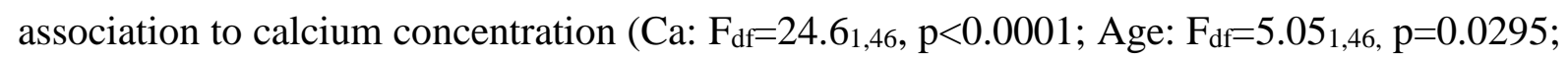
Ca*Age: $F_{d f}=8.31_{1,46} ; p=0.0060$, Figure 3 ), potentially connected to intercorrelation between $\mathrm{Ca}$ and $\mathrm{Pb}$ levels.

\subsection{Oxidative Status}

Correlations between metals and oxidative status markers (tGSH, GSH:GSSG, SOD, CAT and GP), were observed for the most part in relation to SOD and CAT. In specific, CAT correlated negatively with the metals $\mathrm{Cu}(\mathrm{r}=-0.43, \mathrm{p}<0.01, \mathrm{n}=46), \mathrm{Ni}(\mathrm{r}=-0.39, \mathrm{p}<0.01, \mathrm{n}=46)$ and $\mathrm{Mn}$ $(\mathrm{r}=-0.32, \mathrm{p}=0.03, \mathrm{n}=46)$. SOD correlated negatively with $\mathrm{Cu}(\mathrm{r}=-0.34, \mathrm{p}=0.02, \mathrm{n}=45)$ and $\mathrm{Co}$ $(\mathrm{r}=-0.33, \mathrm{p}=0.03, \mathrm{n}=45)$, but positively with $\mathrm{Pb}(\mathrm{r}=0.32, \mathrm{p}=0.03, \mathrm{n}=45)$, As $(\mathrm{r}=0.36, \mathrm{p}=0.02$, $\mathrm{n}=45)$ and $\mathrm{Ca}(\mathrm{r}=0.37, \mathrm{p}=0.01, \mathrm{n}=45)$. Total glutathione also showed a positive association with $\mathrm{Ca}(\mathrm{r}=0.29, \mathrm{p}<0.05, \mathrm{n}=46)$, while GSH negatively correlated with $\mathrm{Se}(\mathrm{r}=-0.35, \mathrm{p}=0.02, \mathrm{n}=46)$. We observed no significant relationships between biometrics and oxidative status.

We found that $\mathrm{PC} 2$ of metals ( $\mathrm{As}, \mathrm{Cd}, \mathrm{Co}, \mathrm{Cu}, \mathrm{Ni}$ and $\mathrm{Pb}$ ), and year predicted $\mathrm{SOD}$ activity (Table 3, Figure 4). SOD activity was higher in 2015 and positively related to PC2 (Table 3, Figure 4), probably due to elevated concentrations of $\mathrm{Pb}$ and As (main components of PC2) found around Lieto in 2015. Instead, PC1 showed a negative association with CAT (Table 3$)$. Means $( \pm \mathrm{SD})$ of oxidative status markers are presented in supplementary Table S3.

\section{Discussion}

Metal concentrations in the feces of $M$. daubentonii reflected the exposure to ambient contamination. Annual variations were also observed for most elements quantified. Calcium and zinc levels differed between males and females. Superoxide dismutase and catalase varied with the exposure to a combination of metals. Additionally, parasite prevalence was higher close to the pollution source.

Copper, cobalt and nickel were three of the metal elements found at elevated concentrations in the bats living around the smelter. This is consistent with studies on passerine 
bird species around the smelter area, where same metals have been found at larger concentrations when compared to clean site groups (Eeva and Lehikoinen 1996, Berglund et al. 2011), explained by the historical atmospheric metal deposition of copper, nickel and other smelting by-products of the facility (Kiikkilä 2003). When comparing the values of these elements from our study with literature on bats (see Zukal et al. 2015), we observed that the concentrations were in general comparable to what was reported for guano of other insectivorous bats. For example, compared to the values reported in Zukal et al. 2015, the mean values in our study were lower for copper (126.5 vs $205.7 \mu \mathrm{g} / \mathrm{g} \mathrm{d} . \mathrm{w})$, similar for cobalt (1.3 vs. $2.0 \mu \mathrm{g} / \mathrm{g}$ d.w., minimum value), while ca. 3-times higher for nickel (12.3 vs. $4.5 \mu \mathrm{g} / \mathrm{g} \mathrm{d.w.).}$

The elevated bat fecal values observed, particularly of nickel, are possibly linked to the metal spillage occurrence around the smelter during 2014, where 66 tons of nickel were released into the river adjacent to the smelter, main feeding ground of the bats in study. Furthermore, maximum fecal nickel values in our study corresponded to bats sampled during the same year, suggesting that nickel in feces may reflect the water and sediment nickel concentration. Similar findings have been reported for the frugivorous bat Neoromicia nana and the diminutive serotine bat (Eptesicus diminutus) where nickel in internal organs correlated to ambient nickel concentrations (Zocche et al. 2010, Naidoo et al. 2013). The extraction of nickel is closely associated to cobalt presence, which may explain the elevated concentrations of the latter in bat feces as well. Even though both nickel and cobalt are essential elements, at high enough concentrations they can exert toxic effects by way of oxygen radical production (Valko et al. 2005). Nickel may cause genotoxicity by overproduction of reactive oxygen species (Costa 1996), whereas cobalt may lead to carcinogenic alterations related to the respiratory system (Princivalle et al. 2017), possibly connected to the production of superoxide radicals when cobalt reacts with hydrogen peroxide (Valko et al. 2005). Copper, also an essential element under homeostatic regulation, forms part of active sites of antioxidant enzymes namely catalase, superoxide dismutase and peroxidase (Nieminen and Lemasters 1996). Excess concentration of copper may trigger lipid peroxidation by excessive reactive oxygen species production and depletion of glutathione (Nieminen and Lemasters 1996).

Accumulation of the non-essential cadmium in kidney and liver occurs with time (Goyer 1997). Thus, the long-lived bats may be prone to the toxicity and prolonged exposure of cadmium, even when this occurs at low concentrations. We expected cadmium concentrations to differ between juveniles and adults, especially since the lifespan of $M$. daubentonii in the wild can reach well over a couple of decades. The oldest recorded individual 
from the Myotis genus was 40 years (Podlutsky et al. 2005). However, we did not observe agedependence in concentrations and it is likely that those would only be observable in internal tissues e.g. kidney, and not necessarily in feces (Berglund et al. 2011). Nevertheless, cadmium exposure may exert negative effects due to its interaction with essential elements such as calcium and zinc, which stimulate the decalcification of bones (Scheuhammer 1987, Goyer 1997).

We found lower fecal calcium concentrations in females compared to males, in line with previous findings in an insectivorous bat (Studier et al. 1991). It is possible that the fecal calcium concentrations reflect the sex-dependent absorption efficiencies; seeing that female bats require more calcium especially during lactation and gestation (Booher 2008), they may be more efficient at extracting calcium from the food items compared to males. But considering also that variation of calcium levels in feces within adult females is also lowest among groups, it is not possible to rule out that these low fecal calcium concentrations in our study females may reflect inadequate calcium in the body, and/or exhausted calcium storages during the breeding phase, as suggested by Studier et al. (1991). Understanding this would require measurements of calcium concentrations in internal organs, which were not part of this study. Furthermore, it has been shown that insectivorous bats may also suffer from seasonal deficiencies of calcium (Studier et al. 1994). There is no doubt that the calcium composition in diet, particularly recently consumed items, will account for much of calcium detected in feces. Taking this into account, sex-differences may not only be related to absorption efficiencies between males and females, but also behavioral feeding patterns. For instance, calcium deficiency in female bats may be due to more opportunistic and less selective feeding during the reproductive period (Studier et al. 1991). Regardless of the reasons for the sex-differences in calcium, we observed negative associations between calcium and forearm length, being more relevant in juvenile bats compared to adults, possibly suggesting the vulnerable state of young's calcium metabolism, which may be compromised when exposed to metals known to interact with calcium, such as cadmium and lead (Ruiz et al. 2016).

Lead interferes with calcium absorption at the molecular level by competing for intestinal binding sites (Dauwe et al. 2006). We found unexpectedly high concentrations of lead, averaging $31 \mu \mathrm{g} / \mathrm{g}$ d.w., in feces of bats from the water mill in Lieto. Concentrations of $20.9 \mu \mathrm{g} / \mathrm{g}$ d.w. in guano of Myotis griscenses have been described (Ryan et al. 1992), but maximum concentrations of lead $(370 \mu \mathrm{g} / \mathrm{g}$ in kidney and $2000 \mu \mathrm{g} / \mathrm{g} \mathrm{d} . \mathrm{w}$. in liver) attributed to lead-based paint ingestion with evidence of lead poisoning have been reported in frugivorous 
bats (Zook et al. 1970, Skerratt et al. 1998). Considering that in bats, fecal concentrations are generally higher in feces compared to internal tissue concentrations (Zukal et al. 2015) and the lack of symptoms characteristic of lead poisoning (Sutton and Wilson 1983), it is possible that the fecal lead concentrations found in our study, although seemingly high, relate to internal lead levels below concentrations to cause toxicity. However, it cannot be ruled out such levels of lead exposure may have had negative consequences in other aspects of bat's health, such as the aforementioned calcium disruption. Sources of lead exposure in urban areas originate from industrial emissions (Hariono et al. 1993, Ruiz et al. 2016), lead-based paints in old buildings and exhaust of vehicles running on leaded gasoline. However, the latter two have been banned some decades ago (Clark 1979, US-EPA 1998). Therefore, it is possible that sources of lead may come from a localized point of lead in the old building (water mill) in which the Lieto bats roost. Though, this is only a conjecture and further studies to confirm this are needed.

Zinc and selenium have protective roles against oxidative stress and the deficiency of zinc can compromise the immune system (Valko et al. 2005, Rautio et al. 2010). In our study, zinc in feces varied by sex, although this difference was significant only when considering the year effect. In that sense, the annual differences between metal exposure may have influence zinc values. We found positive associations between zinc with cadmium, copper and nickel. Of these, zinc and cadmium interactions are better documented in literature. For example, a deficiency of zinc contributes to cadmium absorption (Peraza et al. 1998, Reeves and Chaney 2004), while the presence of cadmium reduces zinc absorption, resulting in higher amounts of zinc excreted in feces (Brzóska and Moniuszko-Jakoniuk 2001). The fact that the female bats excreted more zinc than males, could be indicative of an adverse effect of elevated cadmium concentration on females. However, sex-dependent differences in cadmium were not observed. In the same way as explained for calcium, it is possible that sex-related differences in diet items or feeding patterns may play more important roles in determining the observed sex differences in fecal zinc. Selenium provides defense against copper toxicity (Valko et al. 2005). A deficiency of selenium will impair reproduction in wild animals (Allen and Ullrey 2004). In bats, the highest concentration of selenium in liver $(8.96 \mu \mathrm{g} / \mathrm{g} \mathrm{d}$.w.) has been found in Eptesicus fuscus in a study focused on a fungal disease, white-nose syndrome (Courtin et al. 2010). In our study, selenium was below mean and maximum concentrations described for guano of insectivorous bats (Zukal et al. 2015). In a similar manner as with cadmium, selenium concentration varied annually and by location. Interestingly, only selenium and lead were higher in Lieto than Harjavalta compared to the other elements analysed. 
Some of the essential elements analysed in our study ameliorate the toxic effects of non-essential metal elements when consumed in adequate amounts (e.g. zinc, calcium), while others provide antioxidant protection (e.g. selenium). Antioxidants defend the organism from the chemically reactive species formed after oxygen metabolism (Halliwell and Gutteridge 2007). At the same time, the production of such reactive oxygen species (ROS) can increase due to immune reactions, pollution, reoxygenation after hypoxia during hibernation, food scarcity and predation (Costantini 2014). Here, we observed marked differences in catalase activities in our study groups. Catalase is an enzyme with antioxidant function which converts hydrogen peroxide to water and oxygen in instances when hydrogen peroxide concentrations are particularly elevated (Halliwell and Gutteridge 2007, Costantini 2014). The smelter bats presented the lowest catalase activity during the year of accidental metal spillage. Catalase may be inhibited by copper and other metal ions (Gaetke and Chow 2003). Our findings are in line with the observed negative correlations between catalase and levels of non-essential metal elements know for exerting toxicity (e.g. Cd). In addition, we also observed an effect of year and the second principal component of metal elements ( $\mathrm{As}, \mathrm{Cd}, \mathrm{Co}, \mathrm{Cu}, \mathrm{Ni}$ and $\mathrm{Pb}$ ), which main loadings belong to arsenic and lead, on superoxide dismutase activity. Superoxide dismutase, which catalyzes the conversion of superoxide radicals into hydrogen peroxide and oxygen (Halliwell and Gutteridge 2007) presented higher enzymatic activity during our second and on average less polluted sampling year. It is possible that in a similar manner, as described for the Algerian mice (Mus spretus) living in a polluted copper-mine area (Viegas-Crespo et al. 2003), the exposure to elevated metal elements may decrease the superoxide dismutase activity.

Immunotoxicity is described as the weakening of the immune system because of sustained or elevated pollutant exposure (Propst et al. 1999), rendering the individual vulnerable to parasite infestation, among other effects. At the same time, responses to immune challenge (e.g. parasite infestation) can generate reactive oxygen species (Schneeberger et al. 2013, Lilley et al. 2014). In that sense, an immune response to pollutant challenge may activate oxidative enzymes, while pollutants may on their own do the same by causing oxidative stress. In this study, we observed that bats living close to the smelter in Harjavalta had higher parasite infestation compared to the water mill bats from Lieto. In addition, variation between locations in catalase activities was only observed in 2014, the same year in which higher concentrations of cadmium, copper and nickel were detected around the smelter in Harjavalta. Although, the 
speculate that the combination of pollutants and parasites may have contributed to a decrease in the activity of catalase. Even though lower catalase activities in response to a metal pollutant have already been described in other mammals (Ossola et al. 1997), immune marker tests should accompany the current study to support the hypothesis of an additive effect of parasite infestation and pollutant exposure on catalase activity in bats.

The limited alteration found in the other oxidative status markers examined (tGSH, GSH:GSGG ratio, GP) may be explained by the resistance to oxidative stress characteristic of bats, which by their life-history traits i.e. longevity, exposure to drastic oxygen fluctuations (from entering torpor and hibernation) have possibly developed a stronger defense mechanism against the generation of oxygen radicals (Brunet-Rossinni 2004, Wilhelm Filho et al. 2007, Salmon et al. 2009). For example, compared to short-lived small mammals, bats release hydrogen peroxide at lower rates (Brown et al. 2009).

Other factors, such as timing of bat sampling in relation to entering or leaving hibernation (sampling month) are also important to consider. For instance, $M$. daubentonii are lighter in body mass after arousal from hibernation (April) because they have depleted their fat-reserves during the boreal winter. This can affect release of toxicants accumulated in fat into the bloodstream. However, such factor is more relevant when evaluating lipophilic contaminants such as polyaromatic hydrocarbons, which tend to accumulate in adipose tissue (Bayat et al. 2014). Metals, unless found in their organometallic form (e.g. methylmercury, tetraethyl lead) behave chemically different and generally tend not to accumulate in fat (Yates et al. 2014). Another factor to contemplate in the interpretation of fecal metal concentrations is how well they correlate to internal (i.e. organ) concentrations, because the latter are the ones usually representative of potential toxic or adverse effects in the organism. Comparative studies of metal concentrations among different tissues in passerine birds concluded that metal concentrations in feces are not necessarily correlated with internal tissue concentrations (Berglund et al. 2011). In bats, concentrations of non-essential elements ( $\mathrm{As}, \mathrm{Cd}, \mathrm{Pb}$ ) in tissues such as bone and fur may reflect long-term exposure, whereas softer tissues including brain, muscle and blood would represent recent exposure (Hariono et al. 1993). In a similar manner, metal concentrations in feces will most likely reflect recent exposure mostly via diet, water (Studier et al. 1994, Naidoo et al. 2016) and transfer to feces via biliary excretion (Gregus and Klaassen 1986). However, comparative studies of metal concentrations in internal tissues and feces at the individual level from the same study are to our best knowledge lacking for bats, because obtaining internal tissues may require sacrifice of bats. Still, the lack of these 
comparative reference values makes the assessment of toxic effects difficult in this study. Lastly, excretion rates of insectivorous bats which range from 15 to 90 minutes after food ingestion in $M$. daubentonii (Webb et al. 1993), likely make the metal turnover fast. Thus, possibly affecting the metal values observed in feces.

\section{Conclusions}

Our study makes use of a minimally invasive and understudied format (i.e. fecal pellets) to evaluate exposure to metal contaminants in free-ranging bats. The elevated concentrations of metal elements (cadmium, copper, nickel) commonly found in other vertebrate species around the smelter study site (Eeva and Lehikoinen 1996, Eeva et al. 2009) and the correlations between an incidental metal discharge around our polluted study site (smelter) indicate that fresh fecal pellets can be a suitable material to assess metal exposure on an individual basis and show promise for use in biomonitoring studies. However, careful consideration on how representative the fecal metal values are of the internal metal body burden should be taken into account. Significant differences in catalase and superoxide dismutase between our study sites may suggest the onset of physiological stress, possibly caused by excessive non-essential toxic metal concentrations in the environment, although contribution from parasite prevalence cannot be ruled out. To our best knowledge, this is the first study in which metal exposure in relation to oxidative status is reported on an individual basis in non-captive bats. Further studies, adding the evaluation of immune status markers would be valuable in understanding the effect and relation of metal pollutant exposure with oxidative status.

\section{Acknowledgments/ Permits}

Paul Ek and Sten Lindholm (Åbo Akademi) are acknowledged for the heavy metal analysis. We thank Ville Vasko for help during field sampling and Janina Stauffer for advice on oxidative status protocols. Silvia Espín and Pablo Sánchez-Virosta are acknowledged for assistance in laboratory. We thank three anonymous reviewers for their comments on earlier versions of this manuscript. Approval was granted by the Animal Ethics Committee of the University of Turku (license number ESAVI/3221/04.10.07/2013) and Centre for Economic Development, Transport and the Environment collection permit (license number VARELY/948/2015). This study was financed by Academy of Finland (T.E., project: 265859), 
564 the University of Turku Foundation and the Department of Biology (S.R.R.) and the H2020

565 Marie Sklodowska-Curie Actions (T.M.L., 706196).

566

567 
Table 1. The effect of year, sex, age and location on biometrics (body mass and forearm length), hematocrit and parasite prevalence (in wings and fur).

\begin{tabular}{|c|c|c|c|c|c|c|c|c|c|c|c|}
\hline & \multicolumn{3}{|c|}{ Year } & \multicolumn{2}{|l|}{ Sex } & \multicolumn{2}{|l|}{ Age } & \multicolumn{2}{|l|}{ Location } & \multicolumn{2}{|c|}{ Year*Location } \\
\hline & $\mathbf{n}$ & $\mathrm{F}_{\mathrm{df}}$ & $\mathrm{p}$ & $\mathrm{F}_{\mathrm{df}}$ & $\mathrm{p}$ & $\mathrm{F}_{\mathrm{df}}$ & $\mathrm{p}$ & $\mathrm{F}_{\mathrm{df}}$ & $p$ & $\mathrm{~F}_{\mathrm{df}}$ & $p$ \\
\hline Body mass ${ }^{a}$ & 50 & $0.00(1,46)$ & 0.97 & $0.17(1,44)$ & 0.68 & $44.59(1,47)$ & $<0.01$ & $14.71(1,47)$ & $<0.01$ & $2.74(1,45)$ & 0.10 \\
\hline Forearm length ${ }^{a}$ & 50 & $0.00(1,45)$ & 0.99 & $4.92(1,47)$ & 0.03 & $40.83(1,47)$ & $<0.01$ & $1.82(1,46)$ & 0.18 & $1.56(1,44)$ & 0.22 \\
\hline Hematocrit $^{\mathrm{a}}$ & 44 & $0.49(1,41)$ & 0.49 & $0.06(1,39)$ & 0.82 & $0.49(1,40)$ & 0.49 & $1.49(1,42)$ & 0.23 & $0.68(1,38)$ & 0.41 \\
\hline Parasite Wing ${ }^{\mathrm{b}}$ & 51 & $4.56(1,48)$ & 0.04 & $2.25(1,47)$ & 0.14 & $0.21(1,46)$ & 0.65 & $12.33(1,48)$ & $<0.01$ & $0.00(1,45)$ & 0.98 \\
\hline \multirow[t]{4}{*}{ Parasite Fur ${ }^{b}$} & 51 & $0.00(1,47)$ & 0.98 & $2.18(1,46)$ & 0.15 & $0.00(1,45)$ & 0.98 & $0.09(1,47)$ & 0.76 & $6.07(1,47)$ & 0.02 \\
\hline & & & $\mathbf{n}$ & female & $\mathbf{n}$ & male & $\mathbf{n}$ & adult & $\mathbf{n}$ & juvenile & \\
\hline & \multicolumn{2}{|c|}{ Body mass $(\mathrm{g})^{\mathrm{c}}$} & 30 & $8.56 \pm 0.22$ & 20 & $8.06 \pm 0.24$ & 40 & $9.25 \pm 0.16$ & 10 & $7.37 \pm 0.31$ & \\
\hline & \multicolumn{2}{|c|}{ Forearm length $(\mathrm{mm})^{\mathrm{c}}$} & 30 & $37.44 \pm 0.25$ & 20 & $36.70 \pm 0.28$ & 40 & $38.38 \pm 0.19$ & 10 & $35.77 \pm 0.36$ & \\
\hline
\end{tabular}

a Linear Model (LM) with Gaussian distribution.

${ }^{b}$ GLM with Binomial distribution. Final terms in models are bolded. Significance set at $p<0.05$.

${ }^{\mathrm{c} E s t i m a t e s} \pm \mathrm{SE}$ calculated using LMs with sex and age as explanatory variables. $\mathrm{N}$ is the number of individuals. 
Table 2. The effect of year, location (Lieto and Harjavalta), sex and age on the fecal metal concentrations of Myotis daubentonii $(\mathrm{n}=51)$.

\begin{tabular}{|c|c|c|c|c|c|c|c|c|c|c|}
\hline & \multirow{2}{*}{$\begin{array}{c}\text { Year } \\
F_{d f}\end{array}$} & \multicolumn{3}{|c|}{ Sex } & \multirow{2}{*}{$\begin{array}{c}\text { Age } \\
F_{d f}\end{array}$} & \multicolumn{3}{|c|}{ Location } & \multicolumn{2}{|c|}{ Year*Location } \\
\hline & & $p$ & $F_{d f}$ & $p$ & & $p$ & $F_{d f}$ & $p$ & $F_{d f}$ & $p$ \\
\hline Arsenic & $0.50(1,47)$ & 0.48 & $0.13(1,46)$ & 0.72 & $1.51(1,49)$ & 0.23 & $0.82(1,48)$ & 0.37 & $3.08(1,45)$ & 0.09 \\
\hline Calcium & $18.74(1,47)$ & $<0.01$ & $7.16(1,47)$ & 0.01 & $3.17(1,46)$ & 0.08 & $8.16(1,47)$ & $<0.01$ & $0.04(1,45)$ & 0.84 \\
\hline Cadmium & $4.96(1,48)$ & 0.03 & $0.08(1,46)$ & 0.78 & $0.30(1,47)$ & 0.59 & $29.80(1,48)$ & $<0.01$ & $2.18(1,45)$ & 0.15 \\
\hline Cobalt & $14.65(1,47)$ & $<0.01$ & $0.34(1,46)$ & 0.56 & $0.51(1,45)$ & 0.48 & $7.16(1,47)$ & 0.01 & $11.27(1,47)$ & $<0.01$ \\
\hline Copper & $22.25(1,47)$ & $<0.01$ & $0.58(1,45)$ & 0.45 & $0.62(1,46)$ & 0.43 & $28.91(1,47)$ & $<0.01$ & $4.11(1,47)$ & $<0.05$ \\
\hline Lead & $15.29(1,47)$ & $<0.01$ & $0.24(1,45)$ & 0.63 & $0.51(1,46)$ & 0.48 & $37.71(1,47)$ & $<0.01$ & $17.33(1,47)$ & $<0.01$ \\
\hline Manganese & $9.36(1,49)$ & $<0.01$ & $2.06(1,48)$ & 0.16 & $2.20(1,47)$ & 0.14 & $0.19(1,46)$ & 0.66 & $1.57(1,45)$ & 0.22 \\
\hline Nickel & $17.58(1,47)$ & $<0.01$ & $0.32(1,46)$ & 0.57 & $0.50(1,45)$ & 0.48 & $8.88(1,47)$ & $<0.01$ & $5.11(1,47)$ & 0.03 \\
\hline Selenium & $4.07(1,48)$ & $<0.05$ & $0.01(1,45)$ & 0.94 & $0.49(1,46)$ & 0.49 & $9.28(1,48)$ & $<0.01$ & $2.23(1,47)$ & 0.14 \\
\hline Zinc & $4.89(1,48)$ & 0.03 & $4.65(1,48)$ & 0.04 & $1.04(1,45)$ & 0.31 & $1.08(1,47)$ & 0.30 & $2.05(1,46)$ & 0.16 \\
\hline
\end{tabular}

LM with Gaussian distribution. Final terms in models are bolded. Significance set at $p<0.05$

571

Table 3. Effects of metal load and year on the enzymatic activities of superoxide dismutase (SOD) and catalase (CAT).

\begin{tabular}{lllllllllll}
\hline \multicolumn{3}{c}{ PC1 } & \multicolumn{3}{c}{ PC2 } & \multicolumn{3}{c}{ Year } & \multicolumn{3}{c}{ PC1*Year } & \multicolumn{3}{c}{ PC2*Year } \\
& Fdf & $\mathrm{p}$ & Fdf & $\mathrm{p}$ & Fdf & $\mathrm{p}$ & Fdf & $\mathrm{p}$ & Fdf & $\mathrm{p}$ \\
\hline SOD & $0.02(1,41)$ & 0.8837 & $\mathbf{6 . 2 5 ( 1 , 4 2 )}$ & $\mathbf{0 . 0 1 6 4}$ & $\mathbf{2 1 . 3 8 ( 1 , 4 2 )}$ & $<0.0001$ & $1.52(1,39)$ & 0.2253 & $0.92(1,39)$ & 0.3443 \\
CAT & $\mathbf{8 . 0 7 ( 1 , 4 4 )}$ & $\mathbf{0 . 0 0 6 8}$ & $0.04(1,42)$ & 0.8433 & $0.99(1,43)$ & 0.3248 & $2.83(1,40)$ & 0.1006 & $0.41(1,40)$ & 0.5243 \\
\hline
\end{tabular}

PC1 and PC2 are first and second principal components of metals (As, Cd, Co, Cu, Ni and Pb). LM with Gaussian distribution. Final terms in model are bolded. Significance set at $p<0.05$ 

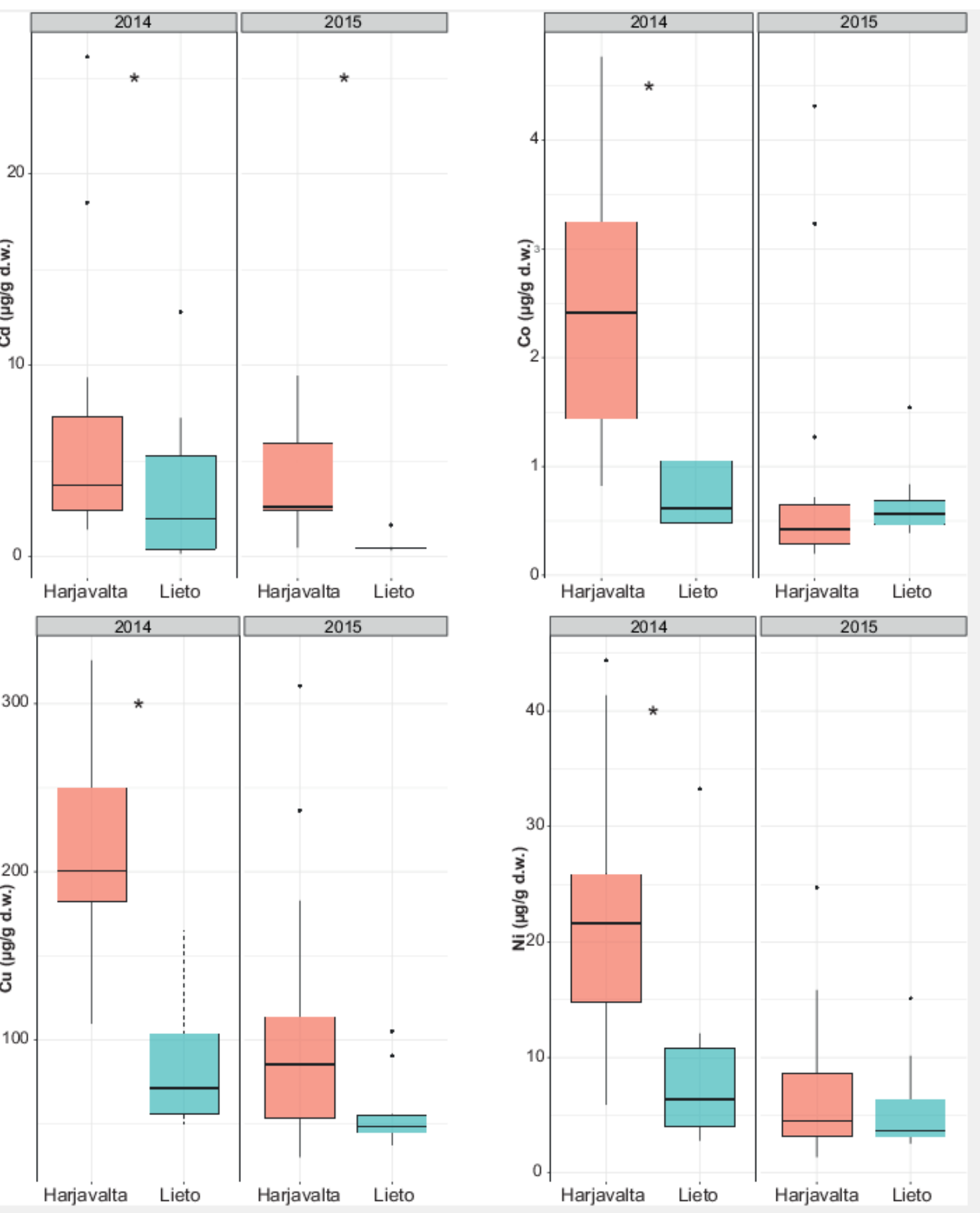

Figure 1. Concentrations ( $\mu \mathrm{g} / \mathrm{g}$ dry weight) of cadmium (Cd), cobalt $(\mathrm{Co})$, copper $(\mathrm{Cu})$ and 575 nickel (Ni) in feces of Myotis daubentonii collected during the years 2014 (Harjavalta: $\mathrm{n}=17$; 576 Lieto: $n=9$ ) and 2015 (Harjavalta: $n=15$; Lieto: $n=10$ ). Asterisks denote significant differences 577 between locations within a year. 


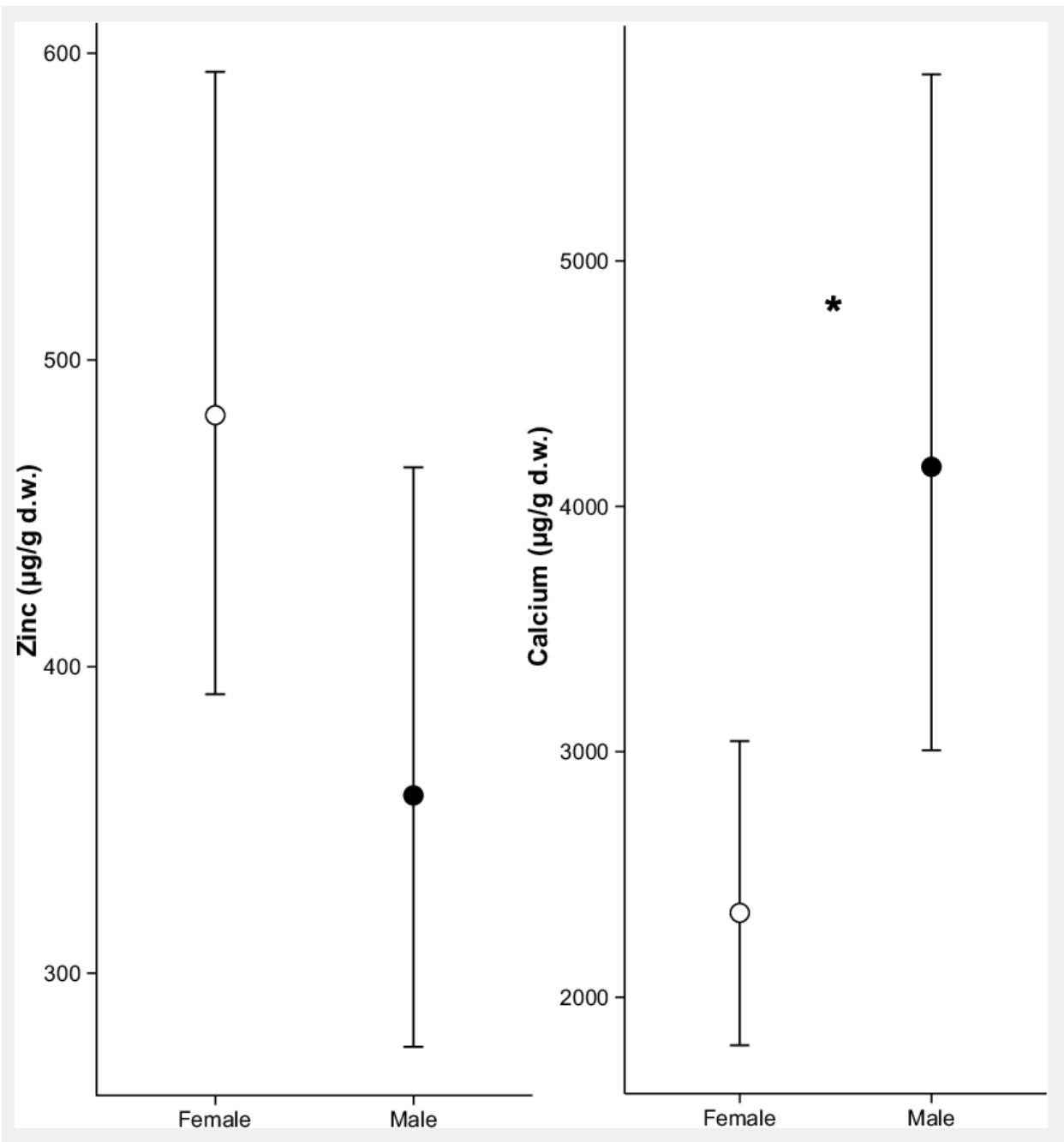

583 Figure 2. Mean $( \pm 95 \% \mathrm{CI})$ Zinc and Calcium concentrations $(\mu \mathrm{g} / \mathrm{g}$ dry weight) in feces of female

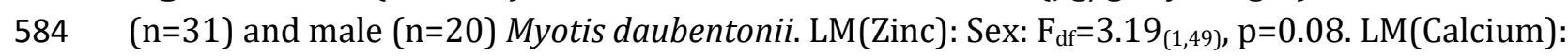
585 Sex: $F_{d f}=7.65_{(1,49)}, p<0.01$. Asterisk denotes significant difference between females and males. 


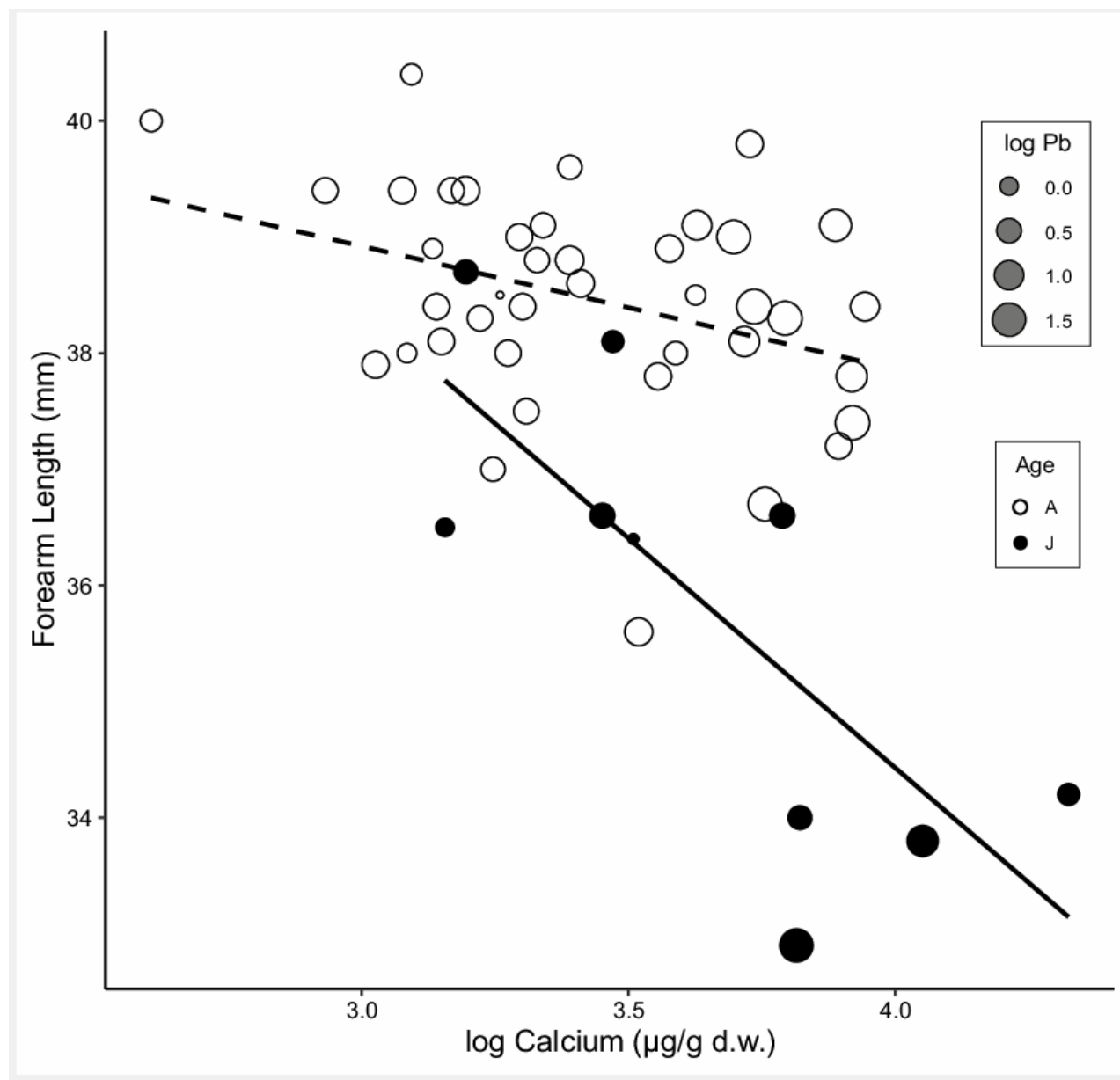

587 Figure 3. Relationship between fecal calcium concentration $(\mu \mathrm{g} / \mathrm{g}$ dry weight) and forearm

588 length (mm). Empty and filled circles denote adults (A) and juveniles (J), respectively;

589 regression lines correspond to adults (dashed) and juveniles (solid); size of the circles denotes 590 the fecal concentrations of lead. LM (Forearm Length): Calcium: $F_{d f}=24.6_{(1,46)}, p<0.0001$; Age:

$591 \quad F_{d f}=5.05_{(1,46)}, p=0.03$; Calcium*Age: $\left.F_{d f}=8.31_{(1,46)}, p<0.01\right)$. 


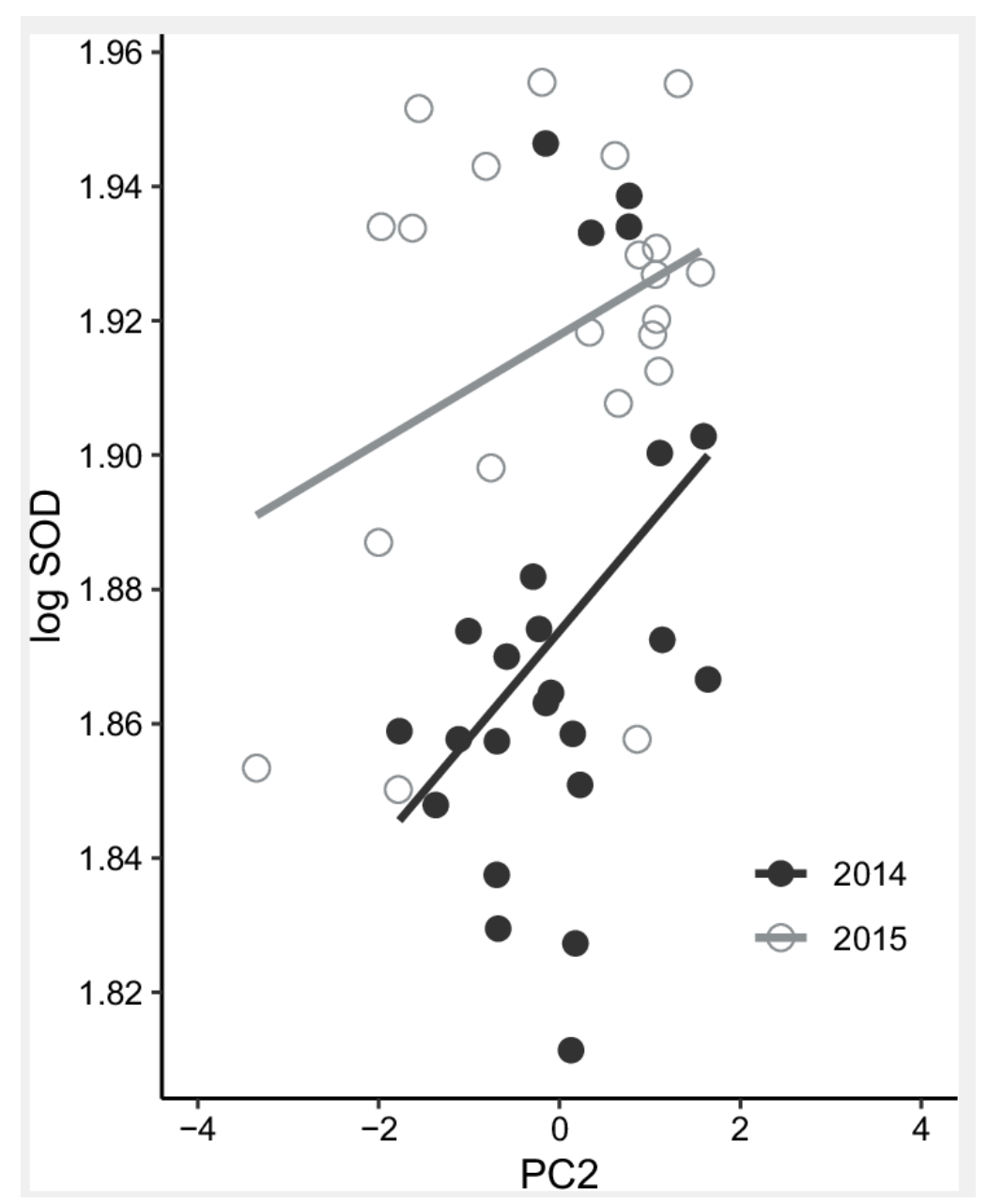

595 Figure 4. Relationship between second principal component (PC2) of metal elements (As, Cd, $596 \mathrm{Co}, \mathrm{Cu}, \mathrm{Ni}$ and $\mathrm{Pb}$ ) and superoxide dismutase (SOD) enzymatic activity. Filled and empty circles 597 are individuals trapped during 2014 and 2015 respectively. LM for SOD are shown in Table 3. 
Table S1. Arithmetic means ( \pm SE) of metal concentrations ( $\mu \mathrm{g} / \mathrm{g} \mathrm{d}$.w.) in feces of Myotis daubentonii per year and location.

\begin{tabular}{|c|c|c|c|c|c|c|c|c|}
\hline & \multicolumn{4}{|c|}{2014} & \multicolumn{4}{|c|}{2015} \\
\hline & \multicolumn{2}{|c|}{ Harjavalta $(n=17)$} & \multicolumn{2}{|c|}{ Lieto $(n=9)$} & \multicolumn{2}{|c|}{ Harjavalta $(n=15)$} & \multicolumn{2}{|c|}{ Lieto $(n=10)$} \\
\hline & mean & $\pm \mathrm{SE}$ & mean & $\pm \mathrm{SE}$ & mean & $\pm \mathrm{SE}$ & mean & $\pm \mathrm{SE}$ \\
\hline As & 5.10 & 1.86 & 1.76 & 0.35 & 9.45 & 5.96 & 7.22 & 2.25 \\
\hline $\mathrm{Ca}$ & 1911 & 277 & 4019 & 866 & 4398 & 1280 & 6658 & 748 \\
\hline Cd & 6.46 & 1.61 & 3.60 & 1.43 & 4.05 & 0.65 & 0.54 & 0.12 \\
\hline Co & 2.47 & 0.31 & 0.75 & 0.12 & 0.90 & 0.31 & 0.66 & 0.11 \\
\hline $\mathrm{Cu}$ & 210.2 & 13.0 & 82.7 & 12.5 & 104.4 & 20.6 & 56.8 & 7.1 \\
\hline Mn & 199.1 & 28.1 & 152.3 & 38.6 & 101.3 & 24.6 & 94.0 & 19.3 \\
\hline $\mathbf{N i}$ & 22.15 & 2.70 & 9.37 & 3.16 & 7.24 & 1.60 & 5.67 & 1.29 \\
\hline $\mathbf{P b}$ & 3.81 & 0.43 & 5.32 & 0.82 & 5.25 & 2.17 & 30.91 & 4.95 \\
\hline Se & 2.21 & 0.29 & 3.91 & 0.60 & 1.91 & 0.51 & 5.32 & 0.83 \\
\hline $\mathrm{Zn}$ & 654.0 & 59.0 & 422.7 & 105.2 & 469.7 & 81.2 & 373.2 & 34.5 \\
\hline
\end{tabular}

602

603

604

605

606

607

608 
Table S2. Correlations between metal elements in feces of Myotis daubentonii.

\begin{tabular}{|c|c|c|c|c|c|c|c|c|c|}
\hline & $\log C a$ & $\log C d$ & $\log C o$ & $\log \mathrm{Cu}$ & $\log M n$ & $\log N i$ & $\log P b$ & $\log S e$ & $\log Z n$ \\
\hline \multirow[t]{2}{*}{$\log A s$} & 0.18 & -0.09 & 0.19 & 0.07 & 0.23 & 0.18 & 0.40 & 0.03 & 0.01 \\
\hline & 0.211 & 0.544 & 0.179 & 0.642 & 0.103 & 0.205 & 0.003 & 0.859 & 0.971 \\
\hline \multirow[t]{2}{*}{$\log \mathrm{Ca}$} & 1 & -0.53 & -0.39 & -0.48 & -0.15 & -0.38 & 0.52 & 0.14 & -0.27 \\
\hline & & $<0.0001$ & 0.005 & $<0.001$ & 0.291 & 0.006 & $<0.0001$ & 0.336 & 0.053 \\
\hline \multirow[t]{2}{*}{$\log C d$} & & & 0.47 & 0.66 & 0.49 & 0.46 & -0.56 & -0.30 & 0.50 \\
\hline & & & 0.001 & $<0.0001$ & $<0.001$ & 0.001 & $<0.0001$ & 0.034 & 0.0002 \\
\hline \multirow[t]{2}{*}{$\log C_{0}$} & & & & 0.77 & 0.57 & 0.72 & -0.09 & 0.01 & 0.62 \\
\hline & & & & $<0.0001$ & $<0.0001$ & $<0.0001$ & 0.520 & 0.947 & $<0.0001$ \\
\hline \multirow[t]{2}{*}{$\log \mathrm{Cu}$} & & & & & 0.68 & 0.75 & -0.36 & -0.19 & 0.72 \\
\hline & & & & & $<0.0001$ & $<0.0001$ & 0.009 & 0.192 & $<0.0001$ \\
\hline \multirow[t]{2}{*}{$\log M n$} & & & & & & 0.49 & -0.05 & -0.17 & 0.77 \\
\hline & & & & & & $<0.001$ & 0.723 & 0.242 & $<0.0001$ \\
\hline \multirow[t]{2}{*}{$\log N i$} & & & & & & & 0.01 & 0.15 & 0.52 \\
\hline & & & & & & & 0.942 & 0.302 & $<0.001$ \\
\hline \multirow[t]{2}{*}{$\log P b$} & & & & & & & & 0.34 & -0.20 \\
\hline & & & & & & & & 0.015 & 0.168 \\
\hline \multirow[t]{2}{*}{ logSe } & & & & & & & & & -0.25 \\
\hline & & & & & & & & & 0.073 \\
\hline
\end{tabular}

$\mathrm{N}=51$, Pearson correlation coefficient (above), $\mathrm{p}$-value (below).

Bolded values are significant correlations. Significance at $p<0.05$ 
Table S3. Oxidative status mean $( \pm S D)$ in red blood cells of Myotis daubentonii per Year and Location.

\begin{tabular}{|c|c|c|c|c|c|c|c|c|c|c|c|c|}
\hline \multirow{2}{*}{$\begin{array}{l}\frac{\text { Year }}{2014} \\
\end{array}$} & \multicolumn{2}{|l|}{ Location } & \multicolumn{2}{|c|}{ GSH:GSSG ratio } & \multicolumn{2}{|c|}{$\mathrm{tGSH}(\mu \mathrm{mol} / \mathrm{mg})$} & \multicolumn{2}{|c|}{ GP (pmol/min/mg) } & \multicolumn{2}{|c|}{ SOD (\% Inhibition) } & \multicolumn{2}{|c|}{ CAT $(\mu \mathrm{mol} / \mathrm{min} / \mathrm{mg})$} \\
\hline & Harjavalta & Mean \pm SD & $n=16$ & $14.29 \pm 12.19$ & $\mathrm{n}=16$ & $22.64 \pm 9.17$ & $\mathrm{n}=16$ & $0.13616 \pm 0.03127$ & $n=16$ & $74.40 \pm 6.12$ & $\mathrm{n}=16$ & $70.69 \pm 21.29$ \\
\hline & Lieto & Mean \pm SD & $n=8$ & $12.98 \pm 4.63$ & $n=8$ & $30.04 \pm 7.07$ & $n=8$ & $0.14797 \pm 0.03307$ & $n=8$ & $76.03 \pm 7.20$ & $n=8$ & $96.42 \pm 11.38$ \\
\hline 2015 & Harjavalta & Mean \pm SD & $n=14$ & $26.82 \pm 16.05$ & $\mathrm{n}=14$ & $33.25 \pm 8.30$ & $n=14$ & $0.18169 \pm 0.06142$ & $n=14$ & $83.17 \pm 6.51$ & $\mathrm{n}=14$ & $95.66 \pm 12.37$ \\
\hline & Lieto & Mean \pm SD & $n=8$ & $20.55 \pm 19.61$ & $n=8$ & $24.07 \pm 6.37$ & $n=8$ & $0.20766 \pm 0.10649$ & $n=7$ & $82.05 \pm 4.60$ & $n=8$ & $97.68 \pm 10.47$ \\
\hline
\end{tabular}


Allen M, Ullrey D (2004) Relationships among nutrition and reproduction and relevance for wild animals. Zoo Biol 23:475-487

617 Bayat S, Geiser F, Kristiansen P, Wilson SC (2014) Organic contaminants in bats: Trends and new issues. 618 Environ Int 63:40-52

Berglund ÅMM, Koivula MJ, Eeva T (2011) Species- and age-related variation in metal exposure and accumulation of two passerine bird species. Environmental Pollution 159:2368-2374

Booher CM (2008) Effects of calcium availability on reproductive output of big brown bats. J Zool 274:38-43

Boyd RS (2010) Heavy Metal Pollutants and Chemical Ecology: Exploring New Frontiers. J Chem Ecol $36: 46-58$

Bradford MM (1976) Rapid and Sensitive Method for Quantitation of Microgram Quantities of Protein Utilizing Principle of Protein-Dye Binding. Anal Biochem 72:248-254

Brown JCL, McClelland GB, Faure PA, Klaiman JM, Staples JF (2009) Examining the mechanisms responsible for lower ROS release rates in liver mitochondria from the long-lived house sparrow (Passer domesticus) and big brown bat (Eptesicus fuscus) compared to the short-lived mouse (Mus musculus). Mech Ageing Dev 130:467-476

Brunet-Rossinni AK, Wilkinson GS (2009) Methods for age estimation and the study of senescence in bats. In: Kunz TH, Parsons S (eds) Ecological and Behavioral Methods for the Study of Bats. Johns Hopkins University Press, pp 315-325

Brunet-Rossinni AK (2004) Reduced free-radical production and extreme longevity in the little brown bat (Myotis lucifugus) versus two non-flying mammals. Mech Ageing Dev 125:11-20

Brzóska M, Moniuszko-Jakoniuk J (2001) Interactions between cadmium and zinc in the organism. Food and Chemical Toxicology 39:967-980

Clark D (1979) Lead Concentrations - Bats Vs Terrestrial Small Mammals Collected Near a Major

642 Costantini D (2014) Oxidative sress and hormesis in evolutionary ecology and physiology. A marriage between mechanistic and evolutionary approaches. Springer, Heidelberg, Germany

644 Costantini D, Meillere A, Carravieri A, Lecomte V, Sorci G, Faivre B, Weimerskirch H, Bustamante P, 645 Labadie $\mathrm{P}$, Budzinski $\mathrm{H}$, Chastel $\mathrm{O}$ (2014) Oxidative stress in relation to reproduction, contaminants, 
647 Courtin F, Stone WB, Risatti G, Gilbert K, Van Kruiningen HJ (2010) Pathologic Findings and Liver 648 Elements in Hibernating Bats With White-Nose Syndrome. Vet Pathol 47:214-219

649 Dauwe T, Snoeijs T, Bervoets L, Blust R, Eens M (2006) Calcium availability influences lead 650 accumulation in a passerine bird. Animal Biology 56:289-298

651 Dietz C, Nill D, von Helversen O (2009) Bats of Britain, Europe and Northwest Africa. A \& C Black, 652 London

653 Duffus J (2002) "Heavy metals" - A meaningless term? (IUPAC technical report). Pure and Applied 654 Chemistry 74:793-807

655 Eeva T, Ahola M, Lehikoinen E (2009) Breeding performance of blue tits (Cyanistes caeruleus) and great 656 tits (Parus major) in a heavy metal polluted area. Environmental Pollution 157:3126-3131

657 Eeva T, Lehikoinen E (1996) Growth and mortality of nestling great tits (Parus major) and pied 658 flycatchers (Ficedula hypoleuca) in a heavy metal pollution gradient. Oecologia 108:631-639

659 Encarnação JA, Becker NI, Ekschmitt K (2010) When do Daubenton's bats (Myotis daubentonii) fly far 660 for dinner?. Canadian Journal of Zoology-Revue Canadienne De Zoologie 88:1192-1201

661 Encarnação JA, Kierdorf U, Ekschmitt K, Wolters V (2006) Age-related variation in physical and

Encarnação JA, Dietz M, Kierdorf U (2004) Reproductive condition and activity pattern of male

Gaetke L, Chow C (2003) Copper toxicity, oxidative stress, and antioxidant nutrients. Toxicology 189:147-163

667 Gerell R, Lundberg KG (1993) Decline of a Bat Pipistrellus pipistrellus Population in an Industrialized 668 Area in South Sweden. Biol Conserv 65:153-157

Goyer R (1997) Toxic and essential metal interactions. Annu Rev Nutr 17:37-50

670 Gregus Z, Klaassen C (1986) Disposition of Metals in Rats - a Comparative-Study of Fecal, Urinary, and

671 Biliary-Excretion and Tissue Distribution of 18 Metals. Toxicol Appl Pharmacol 85:24-38

672 Halliwell and Gutteridge (2007) Free radicals in biology and medicine. Oxford University Press, New 673 York

674 Hariono B, Ng J, Sutton RH (1993) Lead Concentrations in Tissues of Fruit Bats (Pteropus sp) in Urban 675 and Nonurban Locations. Wildl Res 20:315-320

676 Hoffman DJ, Rattner BA, Burton GA, Cairns J (2003) Handbook of Ecotoxicology. Lewis Publishers, USA

677 Huttunen I, Huttunen M, Piirainen V, Korppoo M, Lepistö A, Räike A, Tattari S, Vehviläinen B (2016) A 678 National-Scale Nutrient Loading Model for Finnish Watersheds-VEMALA. Environmental Modeling \& 679 Assessment 21:83-109 
Joint Nature Conservation Committee (2007) Conservation status assessment for Species: S1314 Myotis daubentonii - Daubenton's bat. Second Report by the UK under Article 17 on the implementation of the Habitats Directive from January 2001 to December 2006. Peterborough: JNCC.

683

684

685

686

687

688

689

690

691

692

693

694

695

696

697

698

699

700

701

702

703

704

705

706

707

708

709

710

711

Kannan K, Yun SH, Rudd RJ, Behr M (2010) High concentrations of persistent organic pollutants including PCBs, DDT, PBDEs and PFOS in little brown bats with white-nose syndrome in New York, USA. Chemosphere 80:613-618

Karouna-Renier NK, White C, Perkins CR, Schmerfeld JJ, Yates D (2014) Assessment of mitochondrial DNA damage in little brown bats (Myotis lucifugus) collected near a mercury-contaminated river. Ecotoxicology 23:1419-1429

Kiikkilä O (2003) Heavy-metal pollution and remediation of forest soil around the Harjavalta Cu-Ni smelter, in SW Finland. Silva Fenn 37:399-415

KVVY ry. (2016) Norilsk Nickel Harjavalta Oy. 5.-6.7.2014 tapahtuneen nikkelipäästön vaikutusten selvittäminen. Loppuraportti 2015. Tampere: KVVY ry.

Laine VN, Lilley TM, Norrdahl K, Primmer CR (2013) Population genetics of Daubenton's bat (Myotis daubentonii) in the Archipelago Sea, SW Finland. Ann Zool Fenn 50:303-315

Lilley TM, Stauffer J, Kanerva M, Eeva T (2014) Interspecific variation in redox status regulation and immune defence in five bat species: the role of ectoparasites. Oecologia 175:811-823

Lilley TM, Ruokolainen L, Meierjohann A, Kanerva M, Stauffer J, Laine VN, Atosuo J, Lilius E-, Nikinmaa M (2013) Resistance to oxidative damage but not immunosuppression by organic tin compounds in natural populations of Daubenton's bats (Myotis daubentonii). Comparative Biochemistry and Physiology C-Toxicology \& Pharmacology 157:298-305

Lilley TM, Meierjohann A, Ruokolainen L, Peltonen J, Vesterinen E, Kronberg L, Nikinmaa M (2012) Reed beds may facilitate transfer of tributyltin from aquatic to terrestrial ecosystems through insect vectors in the Archipelago Sea, SW Finland. Environmental Toxicology and Chemistry 31:1781-1787

Lucan RK, Hanak V (2011) Population structure of Daubenton's bats is responding to microclimate of anthropogenic roosts. Biologia 66:690-695

Méndez-Rodríguez LC, Alvarez-Castañeda ST (2016) Assessment of Trace Metals in Soil, Vegetation and Rodents in Relation to Metal Mining Activities in an Arid Environment. Bull Environ Contam Toxicol 97:44-49

Munshi-South J, Wilkinson GS (2010) Bats and birds: Exceptional longevity despite high metabolic rates. Ageing Res Rev 9:12-19

Naidoo S, Vosloo D, Schoeman MC (2013) Foraging at wastewater treatment works increases the potential for metal accumulation in an urban adapter, the banana bat (Neoromicia nana). Afr Zool 48:39-55

Naidoo S, Vosloo D, Schoeman MC (2016) Pollutant exposure at wastewater treatment works affects the detoxification organs of an urban adapter, the Banana Bat. Environmental Pollution 208:830-839 
Naidoo S, Vosloo D, Schoeman MC (2015) Haematological and genotoxic responses in an urban adapter, the banana bat, foraging at wastewater treatment works. Ecotoxicol Environ Saf 114:304-311

Nam D, Yates D, Ardapple P, Evers DC, Schmerfeld J, Basu N (2012) Elevated mercury exposure and neurochemical alterations in little brown bats (Myotis lucifugus) from a site with historical mercury contamination. Ecotoxicology 21:1094-1101

Ngamprasertwong T, Piertney SB, Mackie I, Racey PA (2014) Roosting habits of Daubenton's bat (Myotis daubentonii) during reproduction differs between adjacent river valleys. Acta Chiropterologica 16:337-347

Nieminen A, Lemasters JJ (1996) Hepatic injury by metal accumulation. In: Chang LW, Magos L, Suzuki T (eds) . Lewis Publishers, USA, pp 887-899

Ossola J, Groppa M, Tomaro M (1997) Relationship between oxidative stress and heme oxygenase induction by copper sulfate. Arch Biochem Biophys 337:332-337

Park KJ, Müller CT, Markman S, Swinscow-Hall O, Pascoe D, Buchanan KL (2009) Detection of endocrine disrupting chemicals in aerial invertebrates at sewage treatment works. Chemosphere 77:1459-1464

Peraza MA, Ayala-Fierro F, Barber DS, Casarez E, Rael LT (1998) Effects of micronutrients on metal toxicity. Environ Health Perspect 106:203-216

Pilosof S, Korine C, Moore MS, Krasnov BR (2014) Effects of sewage-water contamination on the immune response of a desert bat. Mamm Biol 79:183-188

Podlutsky A, Khritankov A, Ovodov N, Austad S (2005) A new field record for bat longevity. Journals of Gerontology Series A-Biological Sciences and Medical Sciences 60:1366-1368

Princivalle A, lavicoli I, Cerpelloni M, Franceschi A, Manno M, Perbellini L (2017) Biological monitoring of cobalt in hard metal factory workers. Int Arch Occup Environ Health 90:243-254

Propst T, Lochmiller R, Qualls C, McBee K (1999) In situ (mesocosm) assessment of immunotoxicity risks to small mammals inhabiting petrochemical waste sites. Chemosphere 38:1049-1067

Rautio A, Kunnasranta M, Valtonen A, Ikonen M, Hyvärinen H, Holopainen IJ, Kukkonen JVK (2010) Sex, Age, and Tissue Specific Accumulation of Eight Metals, Arsenic, and Selenium in the European Hedgehog (Erinaceus europaeus). Arch Environ Contam Toxicol 59:642-651

Reeves P, Chaney R (2004) Marginal nutritional status of zinc, iron, and calcium increases cadmium retention in the duodenum and other organs of rats fed rice-based diets. Environ Res 96:311-322

Regoli F, Giuliani ME, Benedetti M, Arukwe A (2011) Molecular and biochemical biomarkers in environmental monitoring: A comparison of biotransformation and antioxidant defense systems in multiple tissues. Aquatic Toxicology 105:56-66

Ruiz S, Espín S, Rainio M, Ruuskanen S, Salminen J, Lilley T, Eeva T (2016) Effects of dietary lead exposure on vitamin levels in great tit nestlings - an experimental manipulation. Environ Pollut 213:688-697 
Ryan JM, Stilwell DA, Morse NJ (1992) An evaluation of contaminant exposure of three endangered bat species in Virginia. U S Fish and Wildlife Service, Environmental Contaminants Branch, Virginia Field Office, White Marsh, Virginia

Salmon AB, Leonard S, Masamsetti V, Pierce A, Podlutsky AJ, Podlutskaya N, Richardson A, Austad SN, Chaudhuri AR (2009) The long lifespan of two bat species is correlated with resistance to protein oxidation and enhanced protein homeostasis. Faseb Journal 23:2317-2326

Scheuhammer AM (1987) The Chronic Toxicity of Aluminum, Cadmium, Mercury, and Lead in Birds - a Review. Environmental Pollution 46:263-295

Schneeberger K, Czirják GA, Voigt CC (2013) Inflammatory challenge increases measures of oxidative stress in a free-ranging, long-lived mammal. J Exp Biol 216:4514-4519

Senthilkumar K, Kannan K, Subramanian A, Tanabe S (2001) Accumulation of organochlorine pesticides and polychlorinated biphenyls in sediments, aquatic organisms, birds, bird eggs and bat collected from South India. Environmental Science and Pollution Research 8:35-47

Sies H (1999) Glutathione and its role in cellular functions. Free Radic Biol Med 27:916-921

Skerratt L, Speare R, Berger L, Winsor H (1998) Lyssaviral infection and lead poisoning in black flying foxes from Queensland. J Wildl Dis 34:355-361

Stauffer J, Panda B, Eeva T, Rainio M, Ilmonen P (2017) Telomere damage and redox status alterations in free-living passerines exposed to metals. Sci Total Environ 575:841-848

Studier EH, Sevick SH, Ridley DM, Wilson DE (1994) Mineral and Nitrogen Concentrations in Feces of some Neotropical Bats. J Mammal 75:674-680

Studier EH, Viele DP, Sevick SH (1991) Nutritional Implications for Nitrogen and Mineral Budgets from Analysis of Guano of the Big Brown Bat Eptesicus fuscus (Chiroptera: Vespertilionidae). Comparative Biochemistry and Physiology A-Physiology 100:1035-1039

Sutton RH, Wilson PD (1983) Lead Poisoning in Grey-headed Fruit Bats (Pteropus poliocephalus). J Wildl Dis 19:294-296

Tchounwou PB, Yedjou CG, Patlolla AK, Sutton DJ (2012) Heavy metal toxicity and the environment. Molecular, Clinical and Environmental Toxicology 101:133-164

US-EPA (1998) Sources of lead in soil: a literature review 747-R-98-001a

Valko M, Morris H, Cronin M (2005) Metals, toxicity and oxidative stress. Curr Med Chem 12:11611208

Vesterinen EJ, Ruokolainen L, Wahlberg N, Peña C, Roslin T, Laine VN, Vasko V, Sääksjärvi IE, Norrdahl K, Lilley TM (2016) What you need is what you eat? Prey selection by the bat Myotis daubentonii. Mol Ecol 25:1581-1594

Viegas-Crespo AM, Lopes PA, Pinheiro MT, Santos MC, Rodrigues PD, Nunes AC, Marques C, Mathias ML (2003) Hepatic elemental contents and antioxidant enzyme activities in Algerian mice (Mus spretus) inhabiting a mine area in central Portugal. Sci Total Environ 311:101-109 
Wada H, Yates DE, Evers DC, Taylor RJ, Hopkins WA (2010) Tissue mercury concentrations and adrenocortical responses of female big brown bats (Eptesicus fuscus) near a contaminated river. Ecotoxicology 19:1277-1284

Walker LA, Simpson VR, Rockett L, Wienburg CL, Shore RF (2007) Heavy metal contamination in bats in Britain. Environmental Pollution 148:483-490

Webb P, Speakman J, Racey P (1993) Defecation, apparent absorption efficiency, and the importance of water obtained in the food for water balance in captive brown long-eared (Plecotus auritus) and Daubenton's (Myotis daubentonii) bats. J Zool 230:619-628

Wilhelm Filho D, Althoff SL, Dafré AL, Boveris A (2007) Antioxidant defenses, longevity and ecophysiology of South American bats. Comparative Biochemistry and Physiology C-Toxicology \& Pharmacology 146:214-220

Yates DE, Adams EM, Angelo SE, Evers DC, Schmerfeld J, Moore MS, Kunz TH, Divoll T, Edmonds ST, Perkins C, Taylor R, O'Driscoll NJ (2014) Mercury in bats from the northeastern United States. Ecotoxicology 23:45-55

801 Zocche JJ, Leffa DD, Damiani AP, Carvalho F, Mendonça RÁ, lochims dos Santos CE, Boufleur LA, Dias $802 \mathrm{JF}$, Moraes de Andrade V (2010) Heavy metals and DNA damage in blood cells of insectivore bats in coal mining areas of Catarinense coal basin, Brazil. Environ Res 110:684-691

804 Zook BC, Sauer RM, Garner FM (1970) Lead Poisoning in Australian Fruit Bats (Pteropus poliocephalus).

805 J Am Vet Med Assoc 157:691-\&

806 Zukal J, Pikula J, Bandouchova H (2015) Bats as bioindicators of heavy metal pollution: history and 807 prospect. Mammalian Biology 80:220-227 